\title{
Integrated Landscape Management to Reduce Biomass Feedstock Access Costs
}

\author{
Mike Griffel, Damon S Hartley, Yingqian \\ Lin, Matthew Langholz \\ January 2021
}

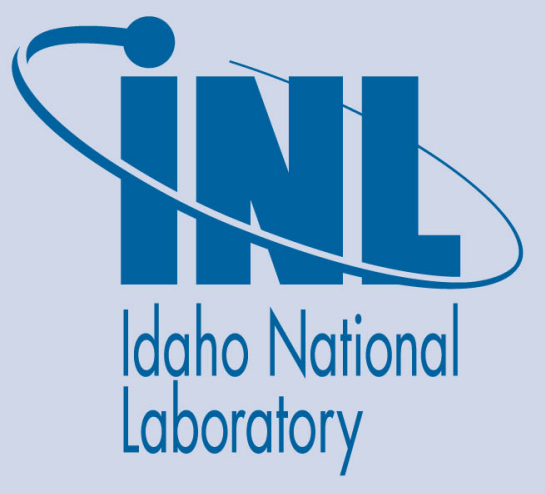

The INL is a U.S. Department of Energy National Laboratory operated by Battelle Energy Alliance 


\section{Integrated Landscape Management to Reduce Biomass Feedstock Access Costs}

Mike Griffel, Damon S Hartley, Yingqian Lin, Matthew Langholz

January 2021

Idaho National Laboratory Idaho Falls, Idaho 83415

http://www.inl.gov

Prepared for the U.S. Department of Energy

Office of Energy Efficiency and Renewable Energy

Under DOE Idaho Operations Office

Contract DE-AC07-05ID14517 
INL/EXT-20-60469

\section{Integrated Landscape Management to Reduce Biomass Feedstock Access} Costs

L. Michael Griffel ${ }^{1}$, Yingqian Lin ${ }^{1}$, Damon S. Hartley ${ }^{1}$, Matthew Langholtz ${ }^{2}$

${ }^{1}$ Idaho National Laboratory

${ }^{2}$ Oak Ridge National Laboratory

\section{Introduction}

Using geospatial, machine learning, and optimization techniques, a field scoring and design framework known as the bioenergy Landscape Environmental Assessment and Design System (bioLEADS) was developed and used to show through modelling that it is possible to reduce biomass feedstock access costs, improve field revenue, and shift intensive row crop production away from subfield areas susceptible to erosion and low in soil organic carbon. The purpose of bioLEADS is to automate agricultural field selection and subfield allocation to perennial energy crop production while incorporating reduced biomass feedstock access costs to support attaining the U.S. Department of Energy (DOE) Bioenergy Technologies Office (BETO) cost targets. In FY2018, a techno-economic analysis (TEA) was developed to evaluate how ILM could be leveraged to reduce biomass feedstock access costs (Griffel et al. 2018). The analysis showed it was possible to reduce access costs by 20 percent from baseline assumptions outlined in the Herbaceous Feedstock 2017 SOT Report (Roni et al. 2017) by shifting costly row-crop inputs away from low-yielding subfield areas in favor of more efficient perennial energy crops. However, during the process of conducting the TEA, need modelling capabilities were identified to improve and modernize ILM analysis efforts and achieve industrial relevance. These capability needs are as follows:

- Field Efficiency Estimation - a method to estimate equipment field efficiency based on field shape and area metrics,

- Field Suitability for Perennial Energy Crop Production - the ability to identify and score agricultural fields most suitable (environmentally and economically) for biomass feedstock production,

- Biomass Feedstock Field Allocation - a technique to allocate county-level biomass feedstock production estimates derived from the Policy Analysis System Model (POLYSYS) in coordination with researchers at Oak Ridge National Laboratory (ORNL),

- Crop Yield Prediction - the ability to access high spatial resolution row crop yield variability data,

- Subfield Crop Allocation - a capability that incorporates data/methods from the previously described capabilities along with necessary assumptions to generate optimal agricultural field designs incorporating energy and row crop production that can maximize economic and environmental outcomes based on user priorities.

Previous ILM modelling efforts have utilized the Landscape Environmental Assessment Framework (LEAF), which has a well-documented history of supporting multiple landscapelevel biomass analysis efforts (Muth et al. 2012, Muth et al. 2013, Nair et al. 2017). At its core, LEAF is comprised of the United States Department of Agriculture (USDA) Revised Universal Soil Loss Equation version 2 (RUSLE2) and Wind Erosion Prediction System (WEPS) models. However, it is not well suited to directly address the capability gaps identified during the TEA. 
During FY19 and FY20, modelling capabilities were developed to fill the identified capability needs that resulted in bioLEADS a new framework to advance the state of ILM modelling. This resulted in the ability to leverage bioLEADS to reduce biomass feedstock access costs beyond the initial target of 20 percent while improving aggregate economic revenue at a field level. Figure 1 shows a diagram of the integration of these capabilities into the bioLEADS framework. Field site suitability for perennial energy crop production is used to score potentially tens of thousands of agricultural fields within a defined region for suitability to produce biomass feedstocks based on criteria spanning agronomic, operational, and environmental domains. Based on the field scores and POLYSYS metadata outputs, county-level biomass feedstock production estimates are allocated in a way that favors higher scoring (more suitable) fields for either perennial energy crop production or excess crop residue collection. Next, specific fields identified for energy crop production where producers want to maintain some traditional rowcrop production (Partial) are identified. Crop yield maps are generated using the crop yield prediction capability and inputted, along with additional assumptions, into a spatial genetic algorithm (GA) to allocate subfield areas to energy and row crop production in ways that maximize field-level economic and environmental outcomes based on user priorities. The following sections will include brief methods descriptions and highlight key results of each bioLEADS component ending in field-level demonstrations of reduced feedstock costs to support BETO cost targets.

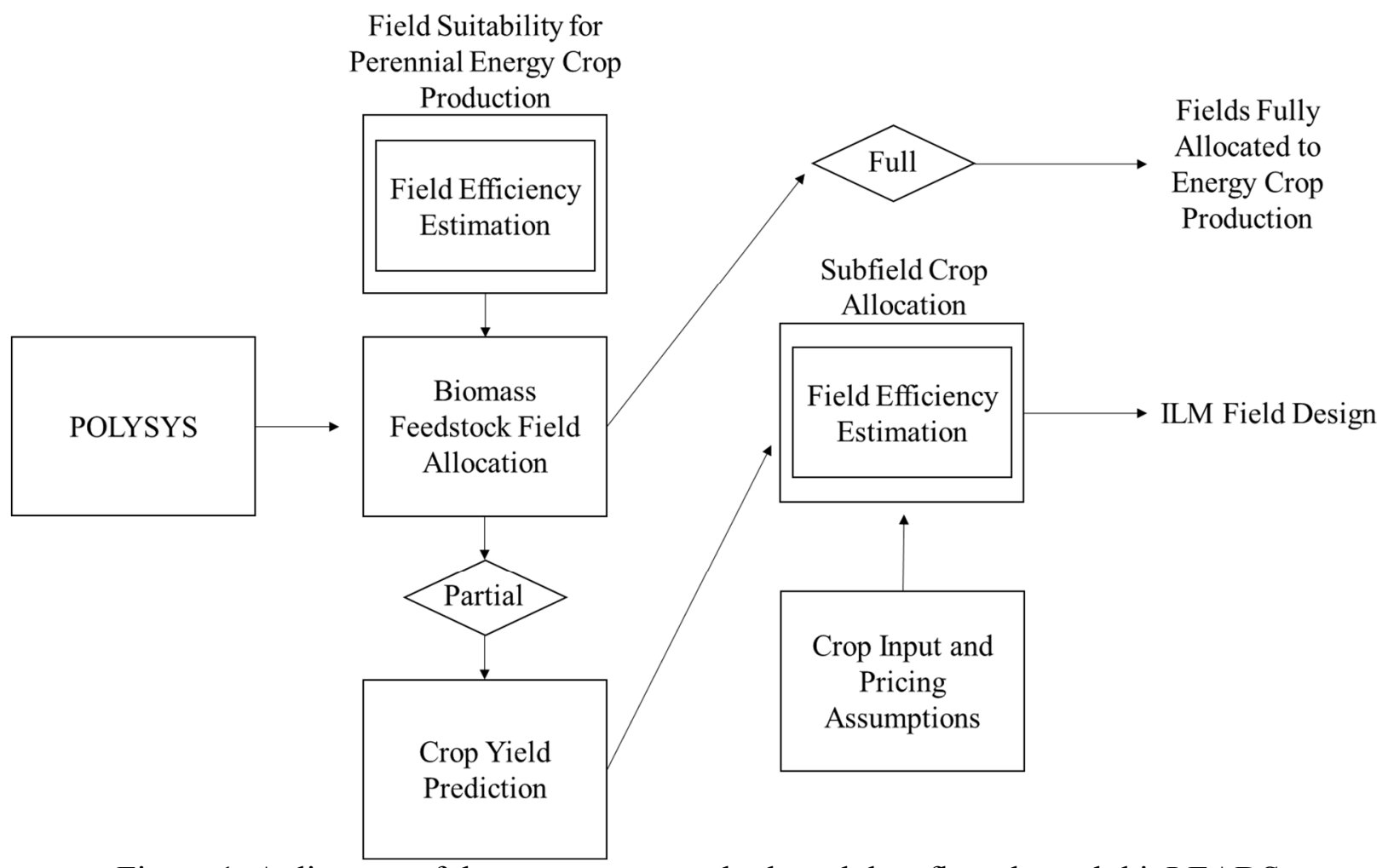

Figure 1. A diagram of the component methods and data flow through bioLEADS.

\section{Field Efficiency Estimation}

For the purposes of this analysis, field efficiency $(F E)$ is defined as follows: 


$$
F E=\frac{T_{d f}}{T_{d f}+T_{d}}
$$

where $T_{d f}$ (delay-free time) is the time to complete the operation with no delays or disengagement and $T_{d}$ (time disengaged) is the time spent where the equipment is disengaged. $T d$ is impacted by field area and geometry which impacts turn efficiency, the number of turns required during the operation at headlands and when navigating around obstructions, and distance travelled in the headlands.

\section{Methods Brief}

Two approaches were developed and evaluated for computational efficiency and accuracy. The first method is based on field boundary shape and area metrics in an equation derived from linear regression and described by Griffel et al. (2020). The second method incorporates a simulation framework to digitally generate actual field operation movement pathways and is described Toba et al. (2020).

\section{Key Results}

Both methods yielded accuracies above $70 \%$ when compared to empirical data. However, to maximize the computational efficiency of bioLEADS, it was decided to incorporate the linear regression method based on field boundary shape and area metrics. Equation 2 (Griffel et al. 2020) shows the field efficiency equation:

$$
F E_{i}=0.179+\left(-0.145 * \ln \frac{P_{i}}{A_{i}}\right)
$$

where $F E$ for field $i$ is derived from linear regression incorporating the field perimeter length $P$ for field $i$ and the farmable area $(A)$ of field $i$.

\section{Field Suitability for Perennial Energy Crop Production}

The field suitability method was developed to score agricultural fields for suitability of energy crop production, such as Panicum virgatum (switchgrass). The capability incorporated multi-criteria site suitability and is intended to be able to score individual agricultural fields at county or regional scales using criteria within agronomic, field operability, and environmental domains. Specifically, it is meant to identify and score fields based on suitable crop rotations, row-crop productivity, vulnerability to erosion, and greater potential for carbon storage. At a high level, suitability for perennial energy crops such as switchgrass are assumed to be higher where row crop yields are lower and environmental vulnerability is higher. Perennial energy crops typically offer an alternative cropping system within the agricultural landscape where traditional row crops are not well suited because of suboptimal soil or topographic features. It has also been shown that switchgrass grown on marginal land had a greater potential ethanol yield than the total yield of corn grain and harvested stover from comparable sites (Gelfand et al. 2013). 


\section{Methods Brief}

Table 1 shows the individual criterion in each domain along with its scoring function. Each criterion is standardized to a value between 0 and 1 . The site suitability value for each field is calculated using a linear fuzzy-logic prediction model (Wu et al. 2011) shown in equation 3 :

$$
S S I_{i}=\sum\left(f_{m, i} w_{m}\right) * \prod b_{n}
$$

where $S S I$ for field $i$ is the site suitability index, $f_{m}$ is the fuzzy value of a criteria $m$ for field $i$, $w_{m}$ is the weight of criteria $m, b_{n}$ is the criteria score of constraint $n$ (Binary value), and $\prod$ is the product. In this analysis, $m=8$ and $n=3$. Binary values ( 0 and 1 ) were assigned to the 3 constraint criteria include land cover, crop rotation, and topography based on the site preference and acceptable range. The land cover and crop rotation metrics were derived from USDA Cropland Data Layers (CDL) for 2019. CDL layers denote specific land uses and are derived from remote sensing and classification analysis coupled with extensive on-the-ground verification to verify classification accuracy. Fuzzy-logic membership functions were built to determine the fuzzy value of the other 8 criteria, including available soil water storage (AWS), National Commodity Crop Productivity Index (NCCPI), field efficiency (FE), soil organic carbon (SOC), water leaching index, distance to water bodies, and soil erosivity index (K). For criteria (3), (4) and (7), areas with lower soil available water, NCCPI and soil organic carbon are more suitable for producing perennial energy crops. The final calculation normalizes the site suitability values to a range of 0 and 1 based on the weighting values. For this analysis, all weighting values were set to 1 .

Table 1. Domains and criteria comprising the Multi-Criteria Site Suitability framework.

\begin{tabular}{|c|c|c|}
\hline Domain & Criteria & Scoring Function \\
\hline \multirow{4}{*}{ Agronomic } & (1) Land cover & $\begin{array}{l}b=1: \text { land cover is crop; } \\
b=0: \text { land cover is non-crop }\end{array}$ \\
\hline & (2) Crop rotation & $\begin{array}{l}b=1: \text { non-specialty crop } \\
b=0: \text { specialty crop }\end{array}$ \\
\hline & $\begin{array}{l}\text { (3) Available soil water storage } \\
\text { within crop root zone depths }\end{array}$ & $\begin{array}{l}f_{m}=1-x_{s m} \\
\text { (Soil Survey Staff, 2019) }\end{array}$ \\
\hline & $\begin{array}{l}\text { (4) National Commodity Crop } \\
\text { Productivity Index }\end{array}$ & $\begin{array}{l}f_{m}=1-x_{s m} \\
\text { (Soil Survey Staff, 2019) }\end{array}$ \\
\hline \multirow[b]{2}{*}{$\begin{array}{l}\text { Field } \\
\text { operability }\end{array}$} & (5) Field efficiency & $\begin{array}{l}f_{m}=x_{s m} \\
(\text { Griffel et al. 2020) }\end{array}$ \\
\hline & (6) Topography (slope) & $\begin{array}{l}f_{m}=x_{s m} \\
b=1: \text { slope } \leq 16.70 \text { degrees } \\
b=0: \text { slope }>16.70 \text { degrees } \\
\text { (Murphy et al. } 1985 \text { ) }\end{array}$ \\
\hline Environmental & $\begin{array}{l}\text { (7) Soil organic carbon in the } 0 \text { - } \\
30 \mathrm{~cm} \text { layer }\end{array}$ & $\begin{array}{l}f_{m}=1-x_{s m} \\
\text { (Soil Survey Staff, 2019) }\end{array}$ \\
\hline
\end{tabular}


(8) Water leaching index

(9) Distance to water bodies $f_{m}=x_{s m}$

(Czymmek et al. 2003)

$f_{m}=\left\{\begin{array}{c}1: 0 \leq x_{9} \leq 200 \\ \frac{\left(x_{9}-200\right)}{3000-200}: 200<x_{9}<3000 \\ 0: 3000 \leq x_{9}\end{array}\right.$

(Houlahan et al. 2004)

(Tran et al. 2019)

(10) Soil erosivity index

$f_{m}=x_{s m}$

(Soil Survey Staff, 2019)

The Field suitability method was used to score individual agricultural fields in a Midwest region spanning 50 counties in southern Nebraska, northern Kansas, and eastern Colorado for suitability for perennial switchgrass production. This area has been used as a herbaceous fuelshed region over the past two years for both ILM and Feedstock Technologies (WBS 1.1.1.2) modelling efforts. This allows for the transfer of ILM benefits and insights to State of Technology (SOT) reports and design cases. Figure 2 shows the footprint of the fuelshed region. The binary crop rotation function was limited to non-perennial row crops common to the region including corn grain, soybeans, spring and winter wheat, sorghum, oats, barley, cotton, and fallow.

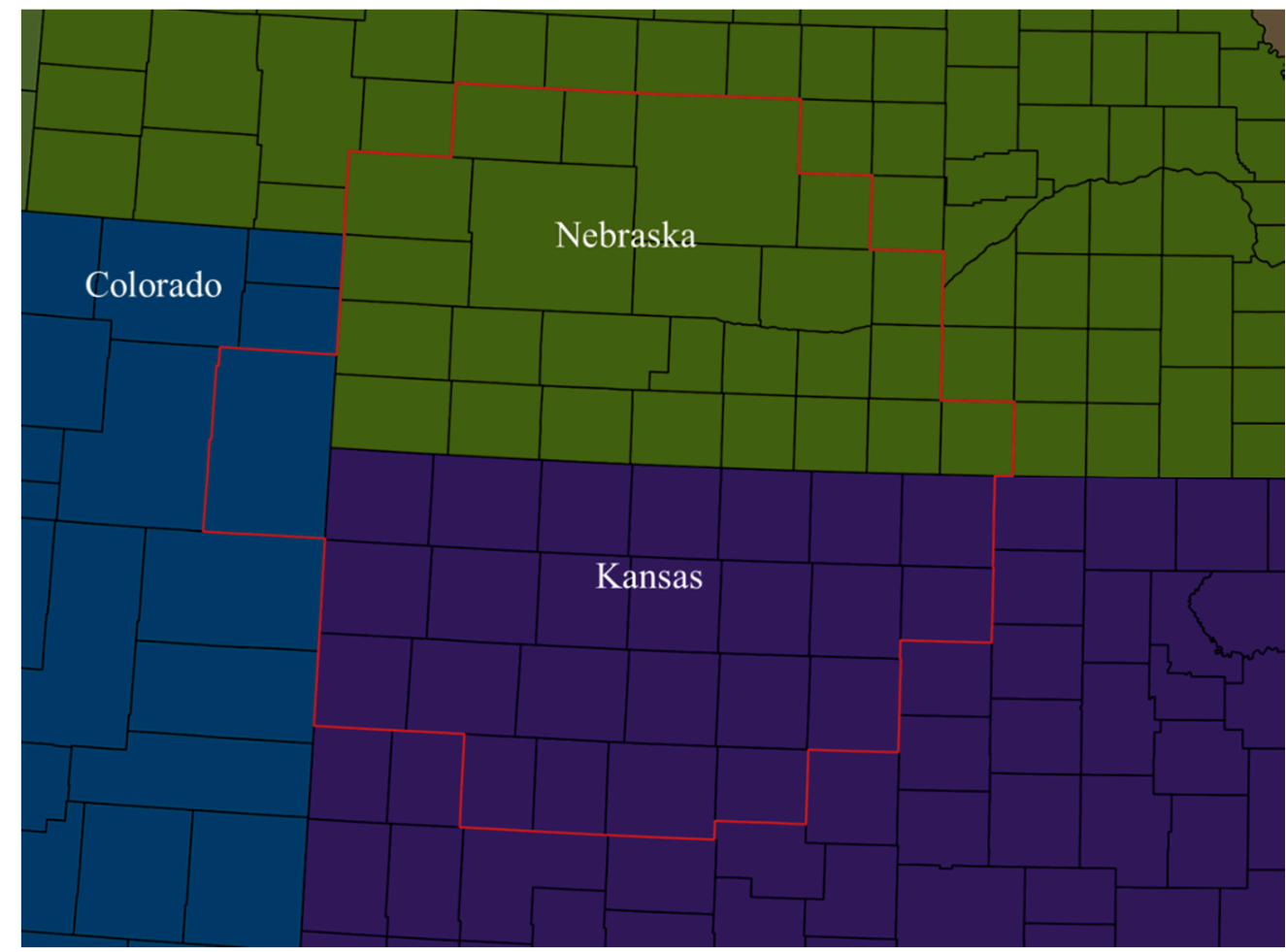

Figure 2. The fuelshed region (outlined in red) spanning northeast Colorado, northwest Kansas, and southwest Nebraska used for ongoing ILM and Feedstock Technologies modelling. 
Individual field boundaries were delineated using publicly available Common Land Unit (CLU) data from 2008. Developed and maintained by the USDA Farm Service Agency (FSA), CLUs represent the smallest unit of land with permanent, contiguous boundaries under a common land cover and land management schema. Although updated annually, current CLU data have not been publicly available since the enactment of The Food, Conservation, and Energy Act of 2008. The latest publicly available dataset was generated in 2008. However, it represents the best-known proxy for field boundaries available for wide-scale modelling efforts requiring individual field boundary delineation.

\section{Key Results}

A total of 336,555 CLU parcels spanning the 50-county region were scored using the criteria listed in Table 1. Out of the initial field boundary group, 164,729 CLU parcels were identified with SSI scores above 0 - those scoring 0 were excluded because of crop rotation or slope restrictions via the binary scoring functions. Figure 3 shows a map of the fields symbolized by the SSI scores and SSI data distribution for the 50-county fuel shed.
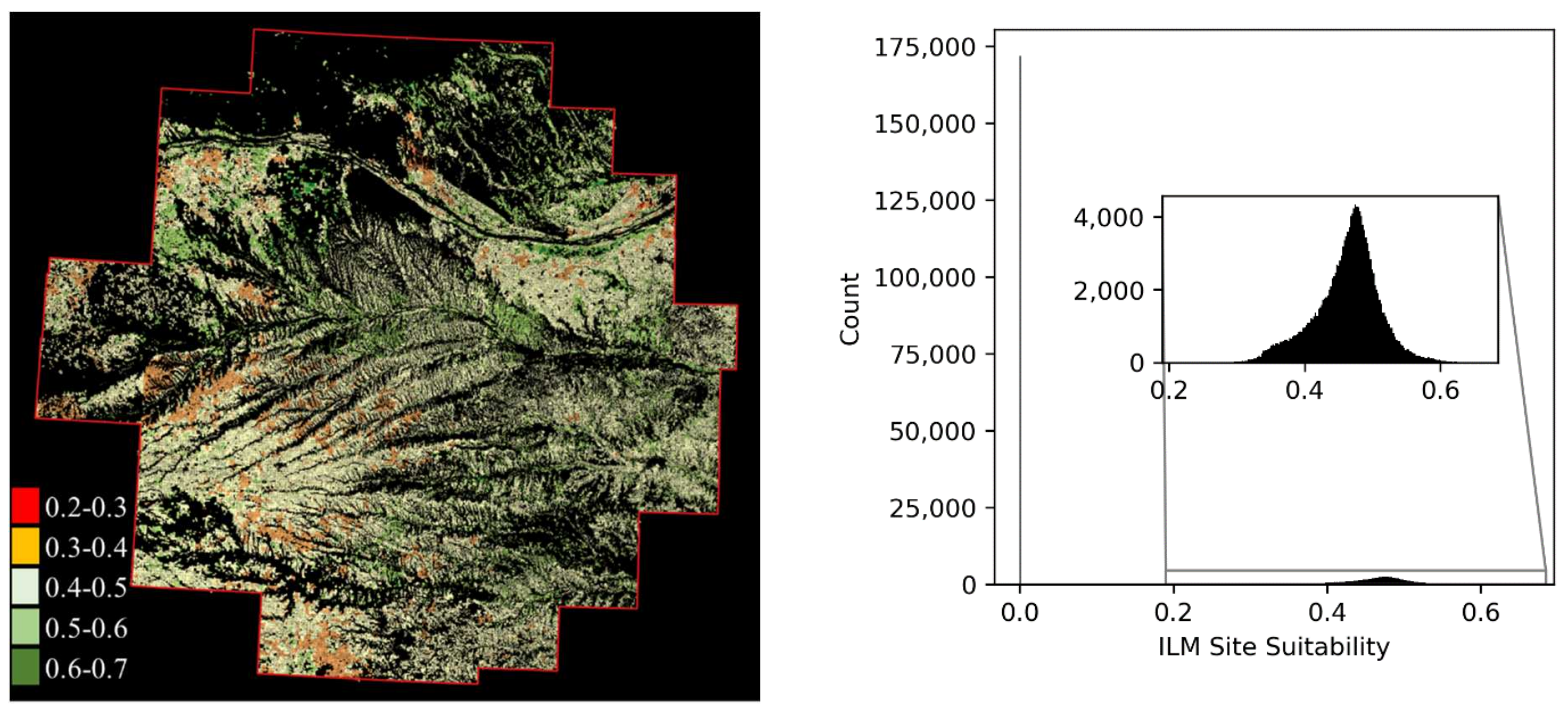

Figure 3. A map of the fields (left) scored for suitability for perennial energy crop production where low-scoring fields are symbolized in the red spectrum and high-scoring fields are symbolized in the green spectrum. The histogram (right) shows the SSI distribution for all fields in the fuelshed region. The inset shows the histogram for fields with SSI values greater than 0 .

Figure 4 shows the resultant standardized distributions and ranges of the individual criteria generating continuous values that, along with the binary functions (not displayed in Figure 3), were used to calculate the final field SSI using the fuzzy logic prediction model. These results indicate that stream proximity, soil organic carbon levels, soil erosivity (K Factor) and field efficiency were the largest influencers of the resultant SSI values for the regions. 


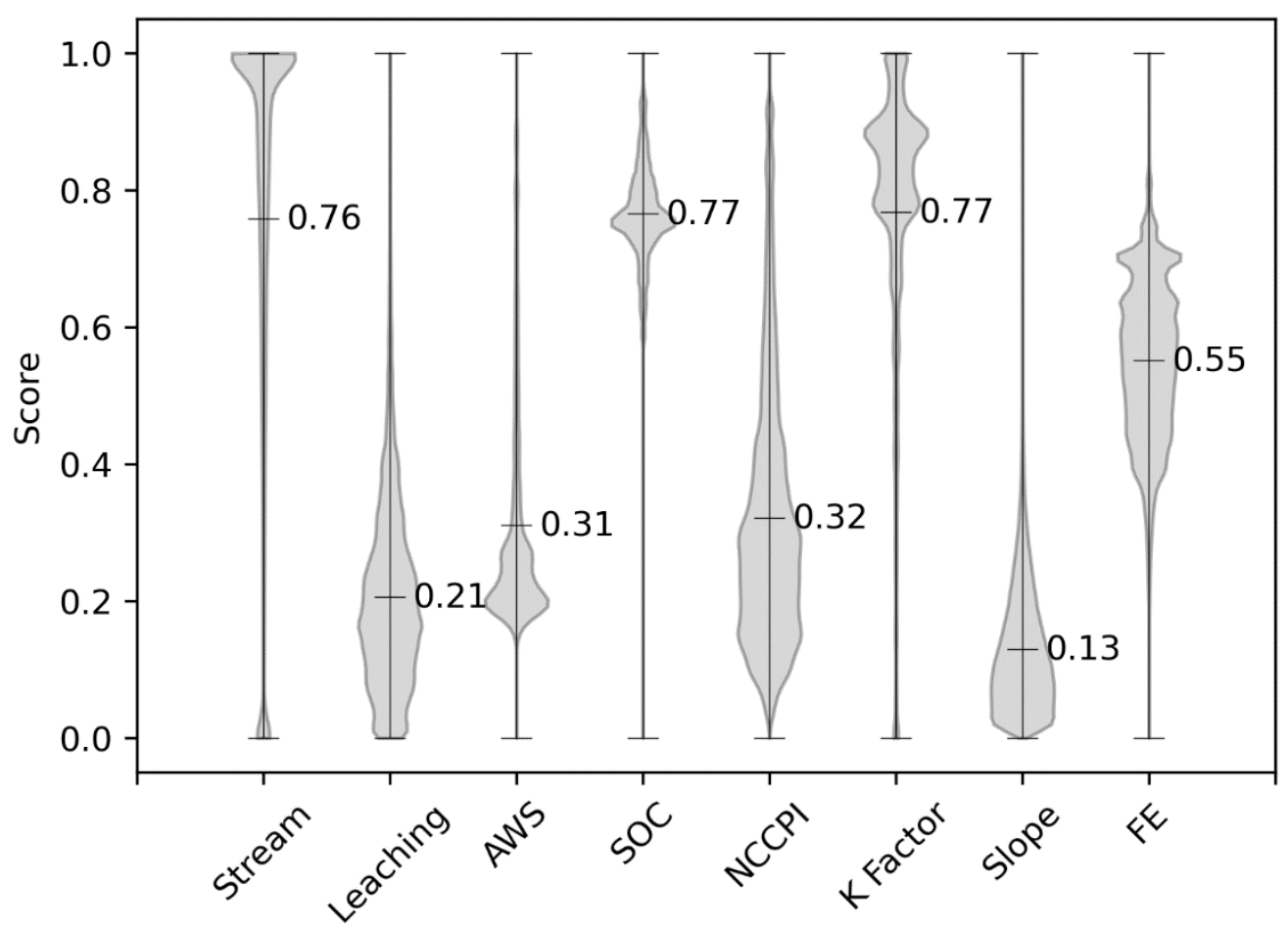

Figure 4. Data distributions of individual criteria with continuous scoring functions for the 50county fuelshed. The horizontal bars represent the criteria score mean which is shown in the associated text.

\section{Biomass Feedstock Field Allocation}

Using the scored fields, potential switchgrass feedstock supplies at a field-level were modeled using POLYSYS outputs provided by researchers at ORNL. POLYSIS is a partial equilibrium model that simulates the U.S. agricultural sector (De la Torre Ugarte and Ray 2000). POLYSYS has been used to explore potential future supplies and prices of biomass feedstocks (USDOE 2016, 2011; Langholtz et al. 2014; Hellwinckel et al. 2015). The model reports potential future biomass supplies and crop production given 1) projected future demands for food, feed, fiber, and export, 2) county-level cropland areas, 3) county-level crop yields and production budgets, and 4) specified prices offered for biomass feedstocks. POLYSYS solves for the most profitable allocation of agricultural lands to the various crop options, from the landowner's perspective, solving at an annual timestep. In addition to potential future biomass supplies, an output of POLYSYS is the county-level land-use transition matrix, i.e., the amount of land drawn from and allocated to each crop type in each year. This provides a basis to explore the county-level croplands that can transition from row crops to perennial energy crops subject to the weighted objectives in the present analysis.

\section{Methods Brief}

For this analysis, a simulation from 2019 to 2028 was executed with a farmgate price of $\$ 66$ $\mathrm{Mg}^{-1}$. POLYSYS generates multiple outputs after a simulation run delivering biomass supply estimates at a county levels along with detailed information on which crops could potentially be replaced for perennial energy crop production. Methods were developed to allocate switchgrass 
production from the county-level POLYSYS outputs to individual fields based on specific crop types and the SSI score where higher scoring fields would have the highest priority. As part of the outputs, POLYSYS generates a probability value for each major crop type by county to transition to switchgrass production by 2028. Those values were used in conjunction with field data to estimate the number of acres of each crop type that would be allocated to switchgrass for this analysis. This is shown in equation 4:

$$
\operatorname{sg} A_{c, i}=P_{c, i} * A_{c, i}
$$

where switchgrass acres $(\operatorname{sg} A)$ for county $i$ drawn from crop acres $c$ are the product of the POLYSYS probability estimate $(P)$ that crop $c$ for county $i$ will be transitioned to switchgrass production by 2028 and the estimated crop acres $(A)$ for crop $c$ in county $i$ derived from the scored field data that contained crop associated crop type information from 2019 CDL data. After calculating the estimated switchgrass acres for each county and crop type, a method was developed to distribute the calculated switchgrass acres to individual fields by allocating to fields based on the associated crop type with the highest SSI score until the estimated acreage was completely allocated. Production values were also allocated using county-level yield estimates derived from POLYSYS outputs. Additionally, given that the POLYSYS outputs also included estimated values for production and acres of total switchgrass by county for 2028, the values calculated as previously described were aggregated and compared to the POLYSYS county-level acreage and production predictions. It is important to note that these outputs could not be used to generate crop-type-specific acreage allocations which is why the previously described method based on crop-transition probabilities was developed.

\section{Key Results}

A total of 9,431 fields were allocated to switchgrass production spanning 17 counties in Kansas. Figure 5 shows a map of the individual fields bounded by the fuelshed boundary and the associated distribution of SSI values of switchgrass fields. The fields are symbolized as shown in Figure 5 based on the SSI - visual analysis and the distribution indicate that the switchgrass allocation method favored higher scoring fields.
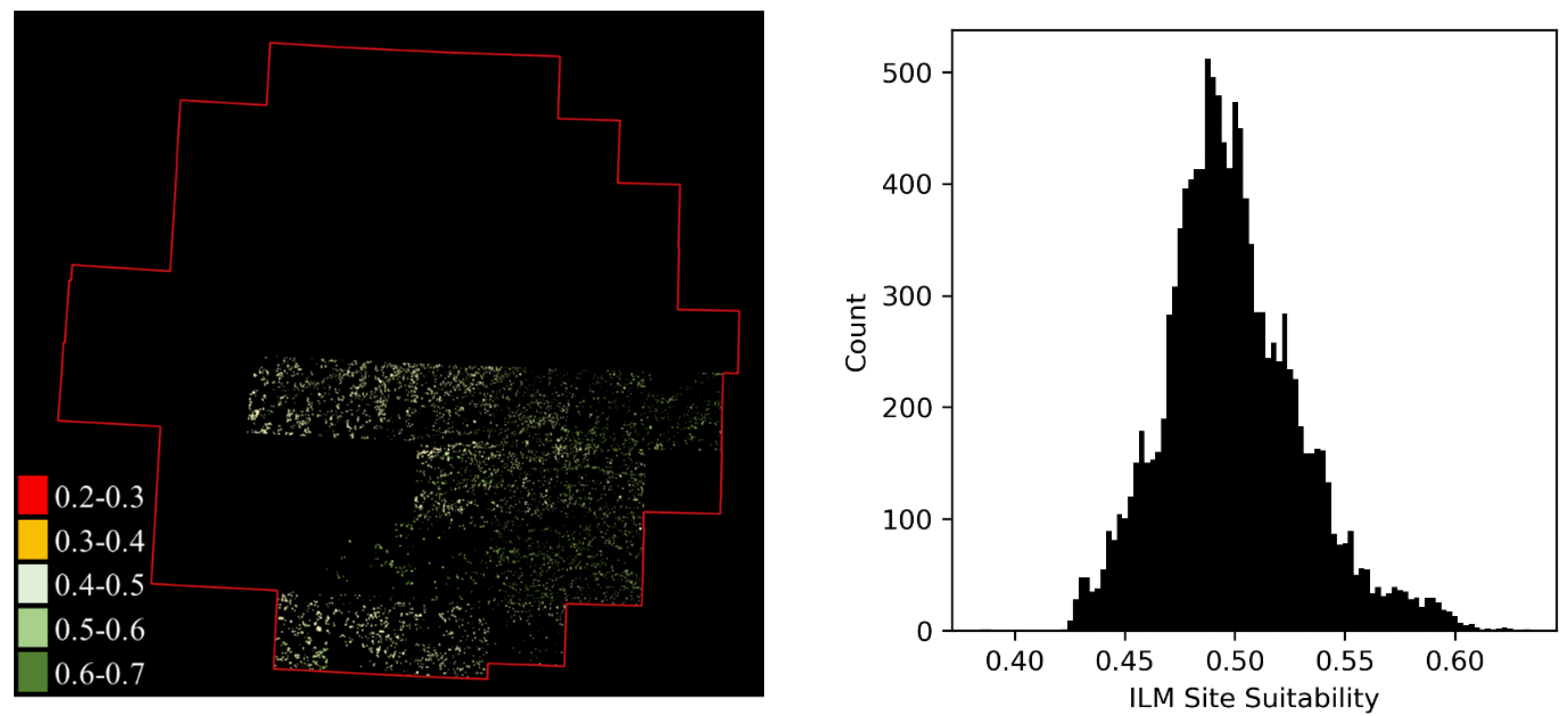
Figure 5. A map of the fields allocated to switchgrass production using the county-level POLYSYS output data spanning 17 counties. The histogram on the right shows the SSI distribution for the switchgrass fields.

The results of the comparison analysis indicate the method developed to allocate cropspecific switchgrass acres by the product of POLYSYS probability values and county and croptype specific area estimates derived from the individual fields using 2019 CDL data and the POLYSYS county level estimates are generally aligned. Total switchgrass acreage allocation using the probability-based function was 806,582 acres and the POLYSYS estimate was 791,443 acres. Total switchgrass production (dt) using the probability-based function was 3,174,146 dt and the POLYSYS estimate was 3,135,704 dt. Figure 6 shows county-level comparisons for both switchgrass acres and production (dt) estimates. The plot on the left shows the acreage comparison by county geoid and the plot on the right shows the production (dt) comparison by county geoid. It is likely discrepancies are the result of different crop-specific acreage estimates by county. The probability-based method calculated crop type acreages by spatially intersecting CLU field boundaries and CDL data and assigning crop types to fields based on the majority of CDL pixels categorizing the crop type. POLYSYS crop acreage estimates are primarily derived from USDA National Agricultural Statistics Service (NASS) data and augmented with CDL data when specific county NASS metrics are not available.

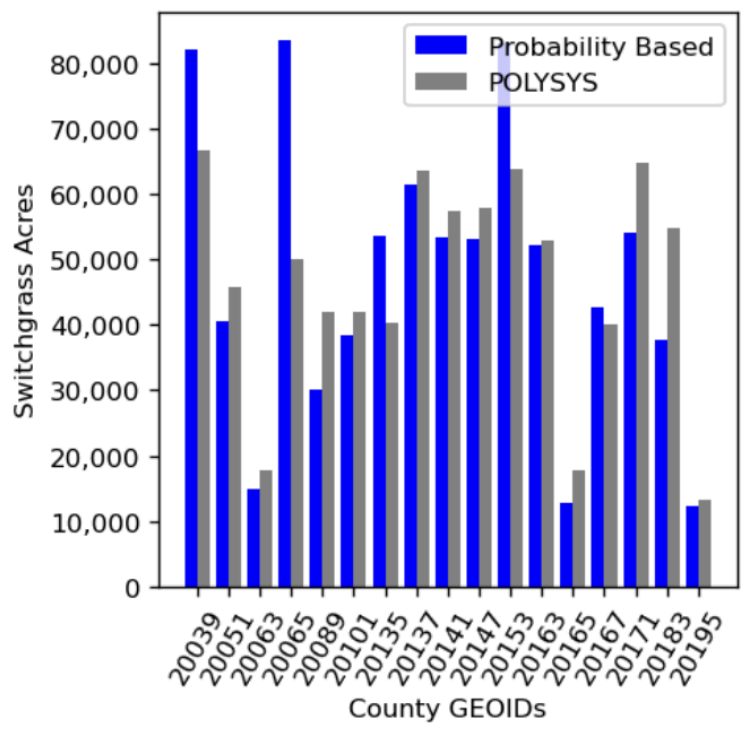

Switchgrass Acreage Comparisons

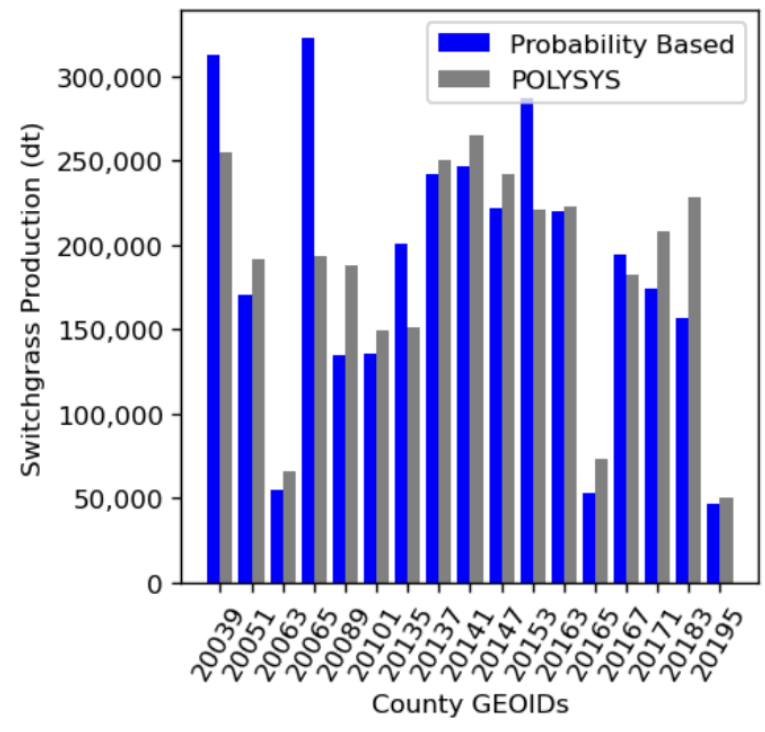

Switchgrass Production Comparisons

Figure 6. Comparison analysis results of county aggregate field-level switchgrass acreage and production estimates of the probability-based method and POLYSYS county-level estimates.

At this juncture, fields have been identified for switchgrass production via the site suitability and allocation methods. Following this, there are two potential pathways for field allocation for farmers and/or landowners to adopt biomass production practices - a full field transition to switchgrass or a partial field transition where farmers integrate switchgrass production at a subfield level while maintaining traditional row-crop production practices in more suitable subfield areas based on economic or environmental constraints. The following sections outline bioLEADS methods supporting advanced subfield designs where switchgrass is integrated into sub-field areas allowing farmers and/or land owners to maintain some row crop production in optimal subfield areas based on economic and environmental preferences. 


\section{Crop Yield Prediction}

A critical dataset to support the integration of switchgrass into sub-field areas are accurate geospatial subfield yield maps. Crop yields drive field economic outcomes when accounting for crop input costs, yield values, and crop prices paid to farmers. Although modern grain harvesters are typically equipped with yield monitors capable of logging this type of data, many farmers have demonstrated an unwillingness to either archive or share this type of data. Past modelling efforts have utilized publicly USDA Soil Survey Geographic (SSURGO) data that provide estimates on soil productivity with the NCCPI metric. However, spatial subfield yield patterns derived from SSURGO can vary significantly from empirical and more accurate harvest monitor yield data. Figure 7 shows a comparison of empirical subfield corn grain yield patterns (left) and associated SSURGO delineations (right). SSURGO data also lacks the spatial resolution to represent subfield yields as continuous gradients, which is how subfield yield patterns typically occur in real-world empirical data. In Figure 7, the harvest monitor data shows the spatially continuous nature of subfield yield patterns (red areas indicate lower yielding areas and green areas represent higher yielding areas). Overall, the harvest monitor data indicates lower yielding subfield areas in the north and south field corners on the west side. The SSURGO data shows a different pattern consisting of only three distinct sub-field yield values represented by the green, red, and orange coloring. Because of these disparities, it was decided to develop a way to leverage publicly available satellite imagery to develop high spatial resolution subfield yield data that is more aligned with empirical harvest monitor data to generate more accurate and industrially relevant advanced ILM field designs incorporating switchgrass production in subfield areas.

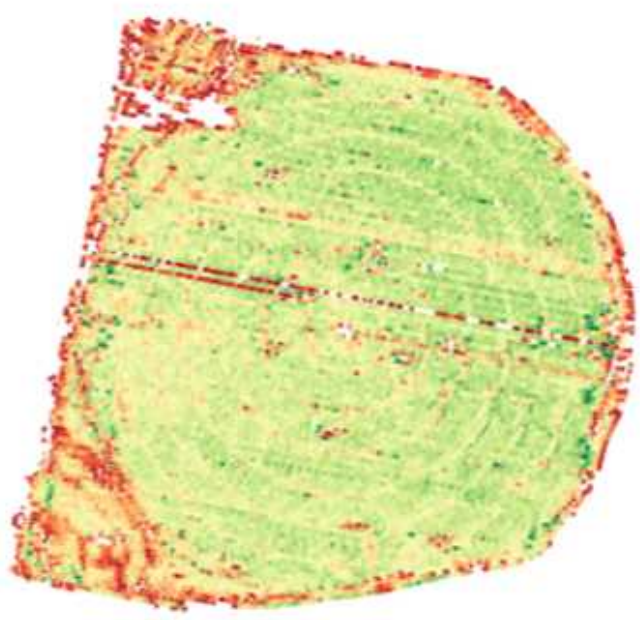

Harvest Monitor Data

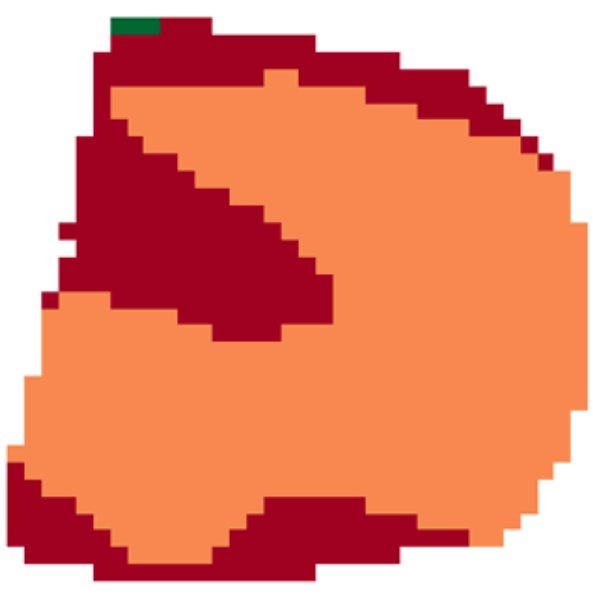

SSURGO Yield Estimation

Figure 7. A comparison of empirical harvest monitor yield data (left) and SSURGO-defined subfield yield variability (right).

\section{Methods Brief}

To realize this capability, artificial neural networks (ANNs) were trained to predict corn grain, soybean, and wheat grain subfield yield values using satellite imagery. Specifically, several hundred megabytes of spatiotemporal crop yield data derived from harvesting equipment 
furnished with yield monitors were compiled via agricultural industry collaborators. The yield data were collected at one-second time intervals and included multiple fields of corn grain, wheat, and soybeans spanning multiple years. Significant effort was made to capture data collected via operators implementing yield monitor calibration practices to support model generalization and accuracy. Given harvest operations tend to occur within "compressed" timeframes requiring long operator hours to complete harvest operations within limited seasons, yield monitor calibration is not a common practice and severely limits availability of statistically sound yield data with which to develop models. The data used for this analysis were confirmed to be derived from operators practicing calibration methods per manufacturer recommendations via personal communications with industry collaborators providing the data.

The analysis incorporated publicly-available open-source remotely sensed data via Earthorbiting satellite platforms specific to the crop production year of the yield data. This was done to minimize project costs and support development of an industry tool that would not require costly data acquisition fees. Although many platforms exist providing this type of data, researchers utilized the European Space Agency's (ESA) Sentinel $2^{1}$ missions within the Copernicus program. Designed for land monitoring at high spatial, temporal, and spectral resolutions, the Sentinel 2 mission provides ideal data for this analysis. The Sentinel 2 Earthobservation mission currently consists of two identical satellite platforms, Sentinel-2A and Sentinel-2B and is capable of providing global coverage approximately every 5 days. The satellites utilize identical sensors and collect EM reflectance in visible, near-infrared (NIR), and shortwave infrared (SWIR) wavelengths at varying spatial resolutions ranging from $10-60$ meters. For this analysis, 20-meter products were used based on known importance to crop phenology attributes such as leaf area index, crop canopy health, and crop canopy moisture content and are shown in Table 2.

Table 2. Sentinel 2 bands and accompanying wavelengths used for yield prediction.

\begin{tabular}{cc}
\hline Band ID & $\begin{array}{c}\text { Center } \\
\text { Wavelength }\end{array}$ \\
\hline Band 2 & $490 \mathrm{~nm}$ \\
Band 3 & $560 \mathrm{~nm}$ \\
Band 4 & $665 \mathrm{~nm}$ \\
Band 5 & $705 \mathrm{~nm}$ \\
Band 6 & $740 \mathrm{~nm}$ \\
Band 7 & $783 \mathrm{~nm}$ \\
Band 8a & $865 \mathrm{~nm}$ \\
Band 11 & $1,610 \mathrm{~nm}$ \\
Band 12 & $2,190 \mathrm{~nm}$ \\
\hline
\end{tabular}

Geoprocessing tools were developed to spatially align yield and remote sensing data to facilitate ANN regression model development, training, and testing regimes. It also included calculating yield estimates derived from SSURGO NCCPI metrics as a criterion with which to base model performance.

\footnotetext{
${ }^{1}$ https://sentinel.esa.int/web/sentinel/missions/sentinel-2
} 


\section{Key Results}

In all cases, ANN models outperformed the previously used SSURGO NCCPI method relative to prediction error. Table 3 shows the comparisons of prediction root mean square errors (RMSE) for each crop model for ANN and NCCPI predictions.

Table 3. ANN and NCCPI yield prediction metrics.

\begin{tabular}{ccc}
\hline Crop & ANN Testing MSE & NCCPI RMSE \\
\hline Corn & 22.81 & 66.02 \\
Wheat & 10.29 & 29.03 \\
Soybeans & 5.63 & 9.25 \\
\hline
\end{tabular}

Figure 8 includes maps and distributions of one of the corn grain fields showing the harvest monitor yield data, the ANN-predicted yield inferences, and the NCCPI-derived yield values. Visual analysis indicates a high level of alignment between the ANN-predicted and empirical harvest monitor data but not with the NCCPI derived values.
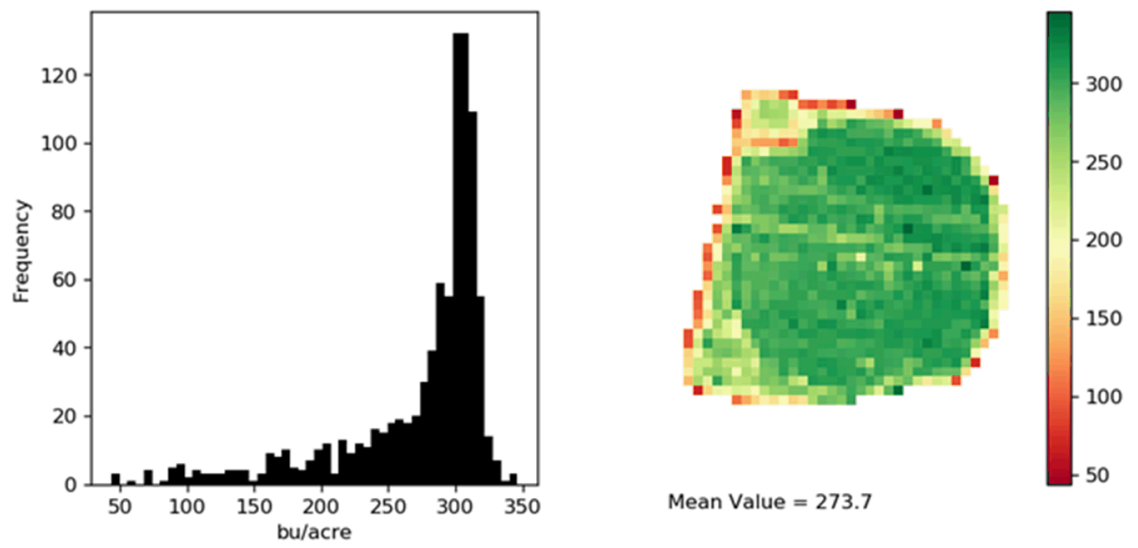

Harvest Monitor Yield
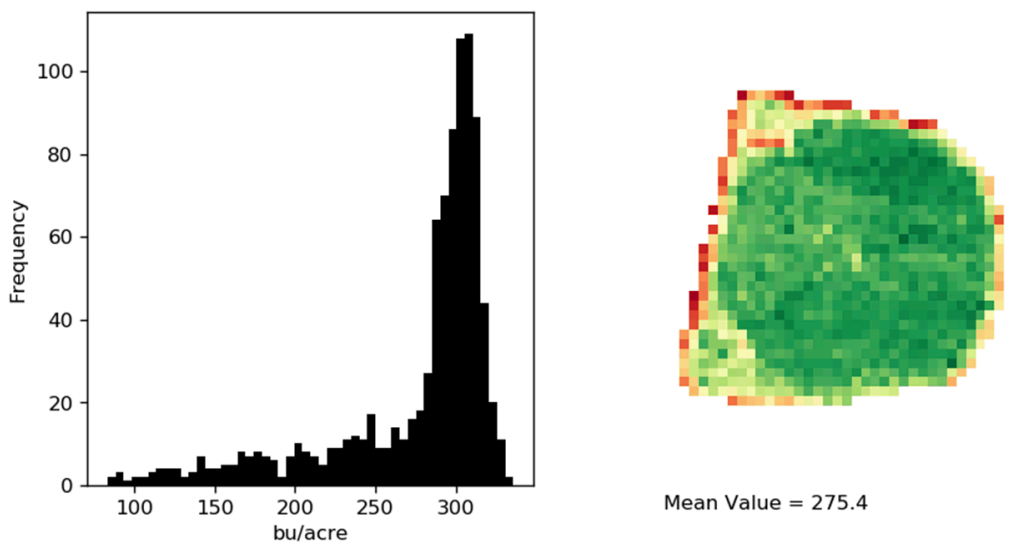

ANN-Predicted Yield 

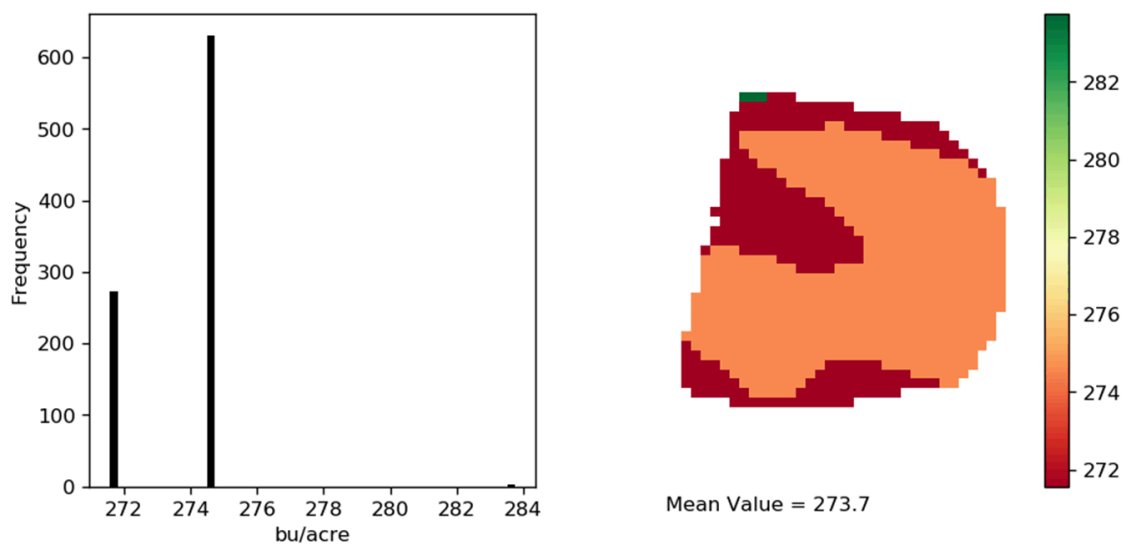

NCCPI-Derived Yield

Figure 8. Comparison of empirical harvest monitor (top), ANN-predicted (middle), and NCCPIderived (bottom) yield maps.

Based on these results, the ANN yield modelling capabilities were incorporated into bioLEADS to develop more accurate and industrially relevant yield data layers to support subfield crop allocation to generate advanced ILM field designs. Four fields were selected from the switchgrass fields data derived from the biomass feedstock field allocation method. The fields were randomly selected from corn grain producing fields for the 2019 crop year with field boundaries that most closely aligned spatially with visual cropping patterns apparent in 2019 Sentinel 2 imagery data, which was used as an input for the trained ANN crop yield prediction model. Field boundaries were spatially edited to fine tune spatial alignment so that only visibly cropped areas were included within the boundary. Only four fields were chosen given the time needed for the computationally intensive subfield crop allocation method described in the subsequent section and the need to run each field through multiple optimization scenarios. Figure 9 shows the predicted yield maps and data distributions for each field. It is important to note that the yield prediction model generated some yield values of 0 for Field 117 and Field 542. The ANN was trained with a distribution containing some near-zero values and it is possible these areas resulted in 2019 corn grain yield values that were close to zero for that crop year. Given that these patterns cannot be confirmed with empirical data without direct communication with the actual farmers, they were left "as is".
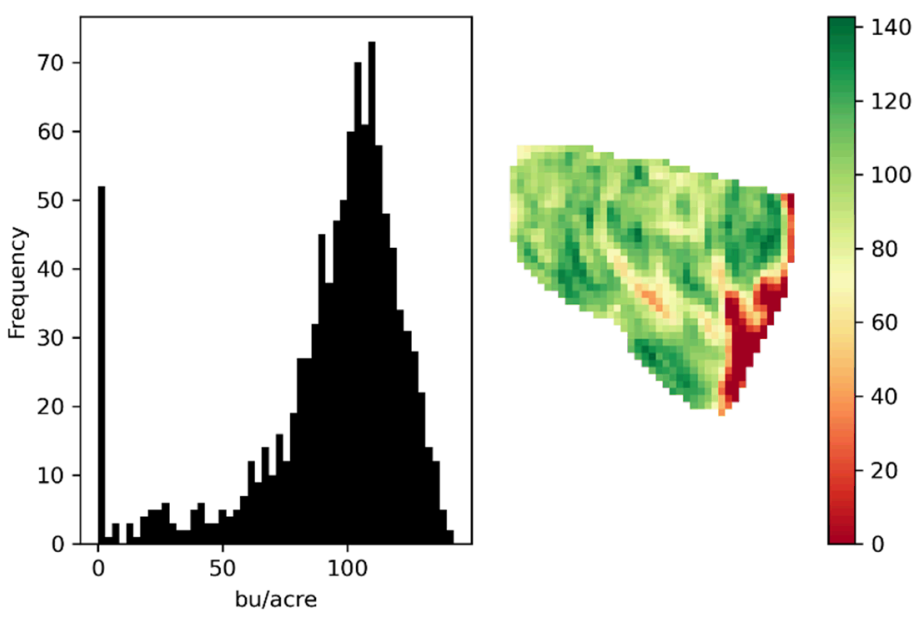
Field 117

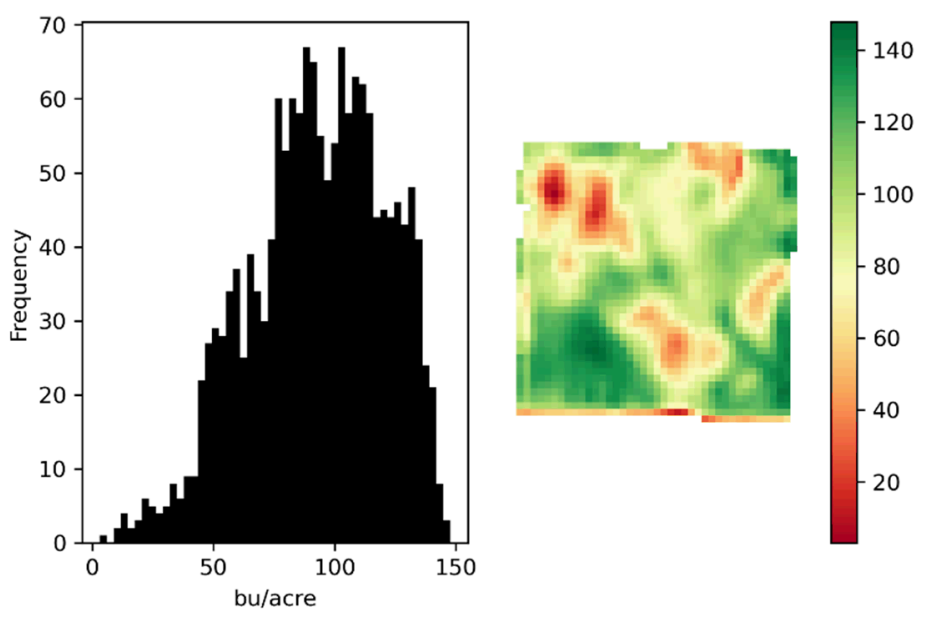

Field 331
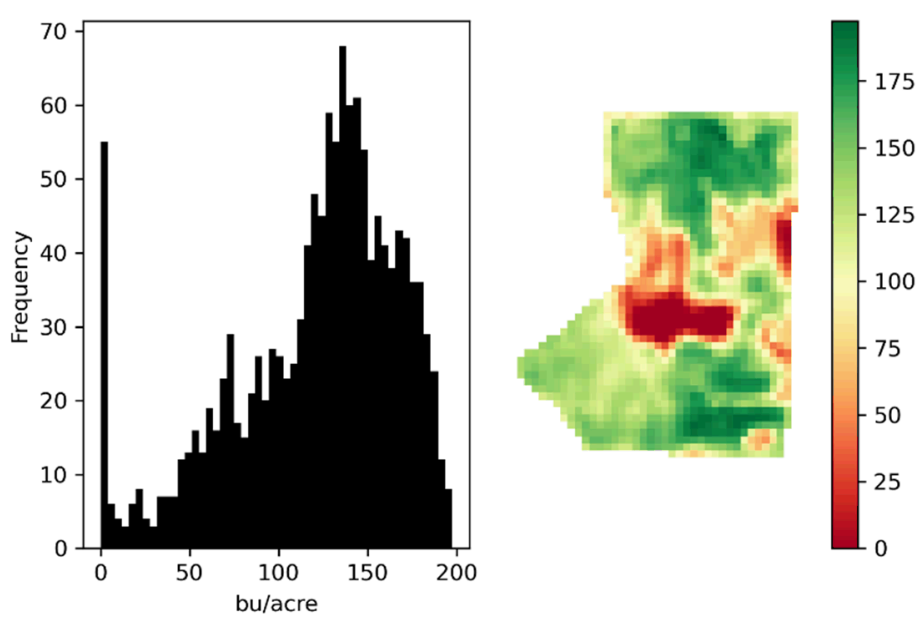

Field 542
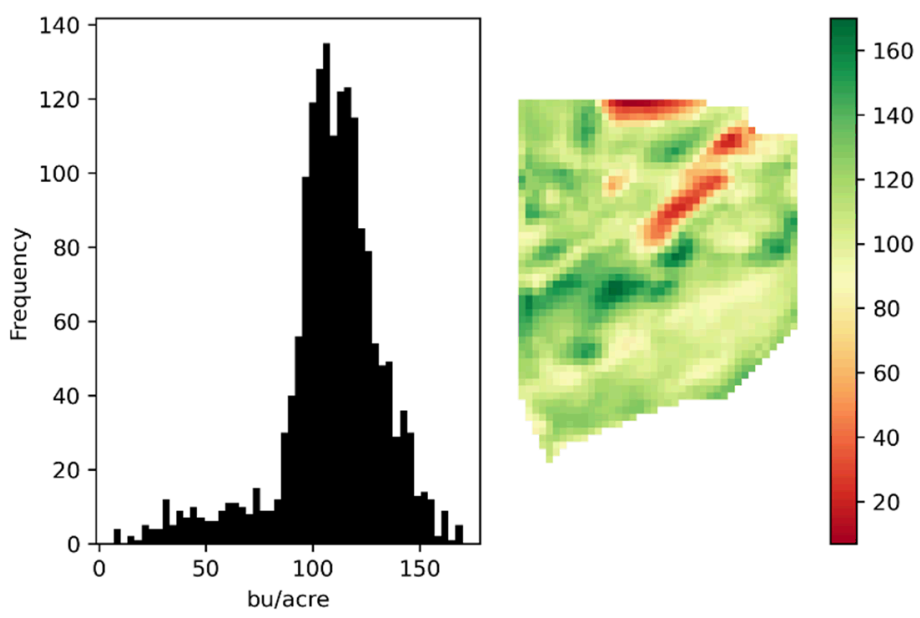

Field 614

Figure 9. Predicted yield maps for the four fields selected for subfield crop allocations.

Table 4 shows the mean corn grain yield from the crop yield prediction method. USDA NASS data shows the mean corn grain yield for Kansas in 2019 to $133 \mathrm{bu} / \mathrm{acre}$. Given that field 
site suitability for perennial energy crop production is intended to prioritize lower yielding fields with additional environmental vulnerabilities making them more suitable for a perennial energy crop such as switchgrass, these yield predictions are in line with known, publicly available metrics.

Table 4. Mean yield values by field from the Crop Yield Prediction method.

\begin{tabular}{cc}
\hline Field & Mean (bu/acre) \\
\hline 117 & 93.28 \\
331 & 92.96 \\
542 & 120.46 \\
614 & 109.49 \\
\hline
\end{tabular}

\section{$\underline{\text { Subfield Crop Allocations }}$}

A geospatial method was developed incorporating an evolutionary GA for subfield crop allocation. Its purpose is to automate subfield allocation of switchgrass and row crop production acres by optimizing user-defined outcomes spanning economic and environmental benefit domains. For this analysis, crop allocation method was used to design the afore mentioned fields with sub-field integration of switchgrass with the goal of maintaining both crop types inside each field boundary.

From a high level, a GA is a metaheuristic designed to find an optimal solution based on natural evolutionary processes. It starts with an initial population of unique individuals (in this case, stochastic field designs), and applies a fitness function to select potential breeding pairs and individuals surviving into the next generation. Children (new field designs) are produced by breeding randomly selected pairs with desirable traits (higher fitness function scores). Over subsequent generations, the process is repeated and includes random occurrences of mutations to avoid convergence at local maxima.

\section{Methods Brief}

The model accepts a common geospatial file format (shapefile) defining the field spatial extent in a grid format with a given size dimension as a parameter. For this analysis, a 10-meter by 10 -meter grid dimension was used. Each grid cell includes a set of attributes needed for the GA fitness function and are as follows.

Bioenergy Crop Site Suitability Score - This metric is calculated by applying the subfield multicriteria site suitability algorithm. For this analysis, the score was calculated based on available water storage (AWS) at the root zone, soil organic content (SOC), erosivity, and topography. Using a linear fuzzy-logic model similar to the function incorporated field suitability, a final score is calculated ranking each subfield grid cell based on its suitability for a perennial crop based on the desire to place switchgrass in environmentally sensitive field areas to reduce soil erosion and enhance soil carbon storage.

Row Crop Yield - This value represents the traditional row crop yield potential captured from either empirical yield data or generated using the previously described crop yield prediction method. 
Switchgrass Yield - A value of $2.2583 \mathrm{dt} /$ acre was used all fields this analysis. This value was based on the 2019 switchgrass yield estimate from the POLYSYS outputs allocated to the individual fields.

Additionally, an input file containing economic assumptions is utilized by the fitness function. It includes data for input and management expenses, pricing estimates, and ecosystem services (ES) valuations for each crop type (row crop and energy crops). Table 5 shows the input parameters used for the four fields described in the previous section. The material and operational costs were based on crop budgets compiled by ORNL researchers to support the BT16 analysis. The corn grain grower payment was calculated from the 10-year mean for Kansas (NASS, 2010 - 2019) and indexed to 2016 dollars for parity with afore mentioned costs. Although the switchgrass grower payment in the 2018 Herbaceous Feedstock State of Technology (SOT) report (Roni et al., 2018) is reported as $\$ 38.87$, it was decided to use a more aggressive cost target of $\$ 26.66$, the same cost associated with three-pass corn stover. In the 2019 SOT report, ILM strategies were incorporated to reduce biomass access costs by $20 \%$ and to increase biomass availabilities in Kansas, Nebraska and Colorado (Roni et al., 2019). The analysis results implied that even with the $20 \%$ reduced cost previously demonstrated in the 2018 TEA, switchgrass was not cost-competitive to be included into the feedstock blend, which suggested that $20 \%$ might not be a low-enough cost reduction target. Therefore, the minimized grower payment for three-pass corn stover at $26.66 \$ /$ dry ton (approximately $30 \%$ cost reduction from $38.87 \$ /$ dry ton) was used as a cost target for the assumed switchgrass grower payment. Additionally, although there are multiple pathways to incorporate potential ecosystem services (ES) valuations, these were not included at this time because of large discrepancies in potential contributions in the literature.

Table 5. Crop input costs and pricing assumptions used in the GA input file.

\begin{tabular}{ccccc}
\hline Crop & $\begin{array}{c}\text { Material } \\
\text { Costs }\end{array}$ & $\begin{array}{c}\text { Operational } \\
\text { Costs }\end{array}$ & Crop Price & $\begin{array}{c}\text { Ecosystem Service } \\
\text { Valuation }\end{array}$ \\
\hline Switchgrass & $\$ 42.83 / \mathrm{acre}$ & $\$ 90.26 / \mathrm{acre}$ & $\$ 26.66 / \mathrm{dt}$ & $\$ 0$ \\
Corn Grain & $\$ 136.53 / \mathrm{acre}$ & $\$ 439.95 / \mathrm{acre}$ & $\$ 4.57 / \mathrm{bu}$ & $\$ 0$ \\
\hline
\end{tabular}

Finally, model parameters used for subfield crop allocation runs are shown in Table 6 . These defined the population size, number of generations, the number of individuals reserved for breeding, the probability of an individual for mutation, and the probability for mutation to occur of a given gene when an individual experiences mutation.

Table 6. GA parameters

\begin{tabular}{cc}
\hline GA Parameter & Value \\
\hline Population Size & 6,000 \\
Number of Generations & 400 \\
Number of Breeding Individuals & 2,700 \\
Probability for Individual Mutation & 0.2 \\
Probability for Gene Mutation & 0.5 \\
\hline
\end{tabular}

Upon initialization, a starting population was instantiated where each grid cell was stochastically assigned a land management - either switchgrass or corn grain production. To fit 
computational limits and adhere to the desire to incorporate both switchgrass and corn grain production within the field, the starting population was limited to initial fields within an approximate range of 40 to 60 percent of switchgrass area. After instantiation, a series of geoprocessing steps was used in conjunction with the crop economic parameters to calculate the overall field revenue accounting for field efficiency. Equation 5 shows the optimization function used for this analysis:

$$
\text { Field Revenue }=\sum_{i=0}^{2}\left[R_{i} \times Y_{i}-\left(C_{M_{i}}+C_{O_{i}} * \frac{F E_{r_{i}}}{F E_{S_{i}}}\right)\right] * A_{i}
$$

where Field Revenue is the total profit of a field design, $R_{i}$ is the revenue received from selling crop $i$, at yield $Y_{i} . C_{M_{i}}$ is the material and services expenses (\$/acre) (seed, chemical, fertilizer, pesticide etc.) for producing crop $i$, and operation $\operatorname{cost} C_{O_{i}}$ (\$/acre) includes operating costs such as labor costs and application costs for herbicide and fertilizer inputs and tillage and harvest operations, $F E_{r_{i}}$ is the reported field efficiency (\%) for farm operations (Hanna, 2016), $F E_{S_{i}}$ is the simulated field efficiency ( $\%$ ) for farm operations using the empirical formulation developed by (Griffel et al., 2020), and $A_{i}$ is the acreage assigned to crop $i$. Additionally, the mean site suitability score is calculated for each field grid cell assigned to switchgrass land management practices.

To account for environmentally vulnerable subfield areas, a site suitability score is assigned to each grid cell. It is assumed a perennial energy crop such as switchgrass is better suited for environmentally vulnerable subfield areas when compared to more intensive annual row crops. Similar to the previously described method to quantify field site suitability for perennial energy crop production, criteria were developed to account for subfield variability in soil water holding capacity, soil organic carbon, erosivity, and topography. Table 7 shows the criteria and functions used for each criterion.

Table 7. Criteria and scoring functions used to generate the subfield site suitability score.

\begin{tabular}{cc}
\hline \multicolumn{1}{c}{ Criteria } & Scoring Function \\
\hline $\begin{array}{l}\text { (1) Available soil water } \\
\text { storage within crop root } \\
\text { zone depths }\end{array}$ & $f_{m}=1-x_{s m}$ \\
\hline (2) Topography (slope) & $f_{m}=x_{s m}$ \\
\hline (3) Soil organic carbon in \\
the 0-30cm layer \\
(4) Soil erosivity index
\end{tabular}

A modified version of the linear fuzzy-logic prediction model (Equation 3) was used to calculate the site suitability score for each subfield grid cell as shown in Equation 6. For this analysis, all criteria were weighted equally with a value of 1. 


$$
S S I_{i}=\sum\left(f_{m, i} w_{m}\right)
$$

where the $S S I$ for grid $i$ is the sum of the products of $f_{m}$ is the fuzzy value of a criteria $m$ for field $i, w_{m}$ is the weight of criteria $m$.

A final score for the field is calculated by standardizing the field revenue and mean switchgrass parcel site suitability scores and summing the products of the resultant values and their associated weighting factors as shown in Equation 7:

$$
\text { Field } \text { Score }_{i}=F R_{i} * W_{f r}+S S I_{i} * W_{s s}
$$

where the Field Score for field $i$ is the sum of the products of the field revenue $(F R)$ for field $i$ and its associated weighting factor $(W)$ and the mean subfield site suitability score $(S S I)$ for the field grids allocated to switchgrass for field $i$ and its associated weighting factor $(W)$. This approach was taken to provide a mechanism to tune the GA optimization space toward economic or environmental benefit outcomes.

After each field design is scored, $n$ number of fields (2,700 for this analysis as shown in Table 6) are randomly selected for pairing by randomly drawing from a group of the highest scoring individuals (i.e. those with the most desirable field design traits). Additionally, a limited sample of lower-scoring fields is added to the breeding pool to maintain "genetic" diversity of the breeding population, or in other words, to avoid local maxima during the evolutionary process. Using cross breeding, the child's grid cell land management class is treated as an individual gene and has an equal chance of coming from either parent. After a child is created, there is a probability for mutation to occur to an individual. If that happens, an additional probability occurs where a specific gene (grid cell) can mutate from its inherited land management class. This cycle is repeated for each generation until the model completes the specified number of generations.

Given the complexity of subfield crop allocation and unknown impacts of varying the Field Score function weighting values, a search space was devised were the GA was tasked with designing each field four times using a $F R$ weighting factor of 1 and four different weight factors for $S S I$ including $1,0.75,0.50$, and 0.25 . This was done to evaluate the effects of equally weighting the SSI and FR metrics and then decreasing the influence of the SSI factor thereby adding emphasis to field economic outcomes.

\section{Key Results}

The results show that for fields 117,331 , and 542, the GA was able to construct field designs incorporating switchgrass at a reduced access cost into subfield areas that outperformed the economic performance of homogenous corn grain production. In all cases, this was achieved by reducing the SSI weight to 0.25 . These results are shown in Table 8 . The GA was not able to converge on a better economic solution for field 614 indicating it might be more suitable in this scenario to leave it entirely in row crop production if field revenue is the primary concern. It is also possible that the GA parameterization (bounded by computational resources) limited the solution space needed to find an optimal solution for switchgrass integration. 
Table 8. Field results for the highest economic returns generated by the GA.

\begin{tabular}{ccccc}
\hline Field & $\begin{array}{c}\text { Baseline } \\
\text { Revenue }\end{array}$ & $\begin{array}{c}\text { ILM } \\
\text { Revenue }\end{array}$ & $\begin{array}{c}\text { Corn Grain } \\
\text { Acres }\end{array}$ & $\begin{array}{c}\text { Switchgrass } \\
\text { Acres }\end{array}$ \\
\hline 117 & $-\$ 11,120$ & $-\$ 8,341$ & 34.7 & 68.5 \\
331 & $-\$ 13,734$ & $-\$ 9,901$ & 36.0 & 122.8 \\
542 & $\$ 3,422$ & $\$ 4,564$ & 91.0 & 44.0 \\
\hline
\end{tabular}

Figure 10 shows maps of the final field designs and plots of the evolution of the field revenue and switchgrass area SSI scores over the 400-generation run. Purple regions in the field plot maps denote switchgrass production and yellow areas symbolize corn grain production.

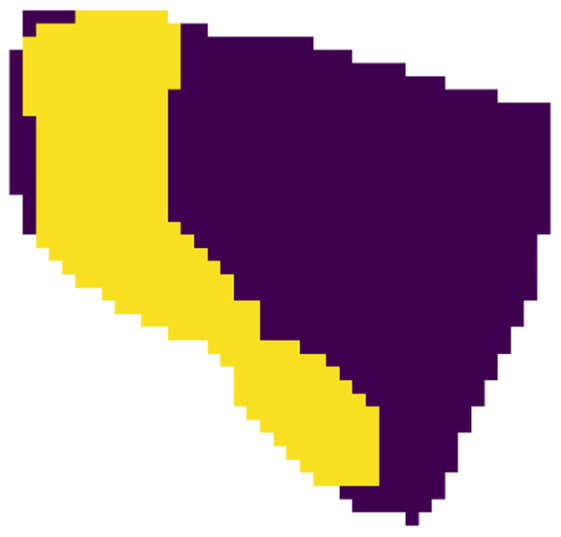

Field 117

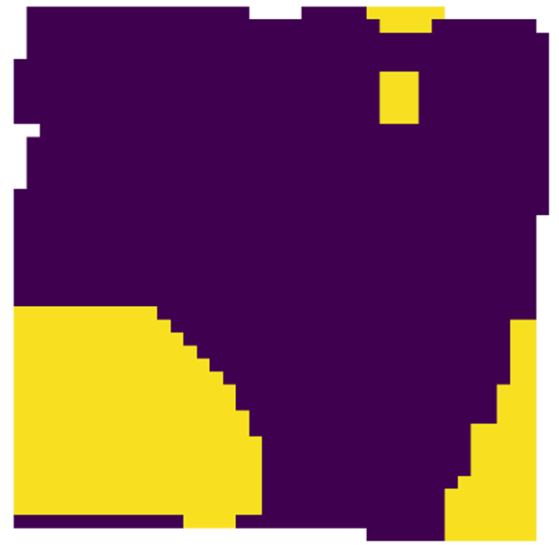

Field 331
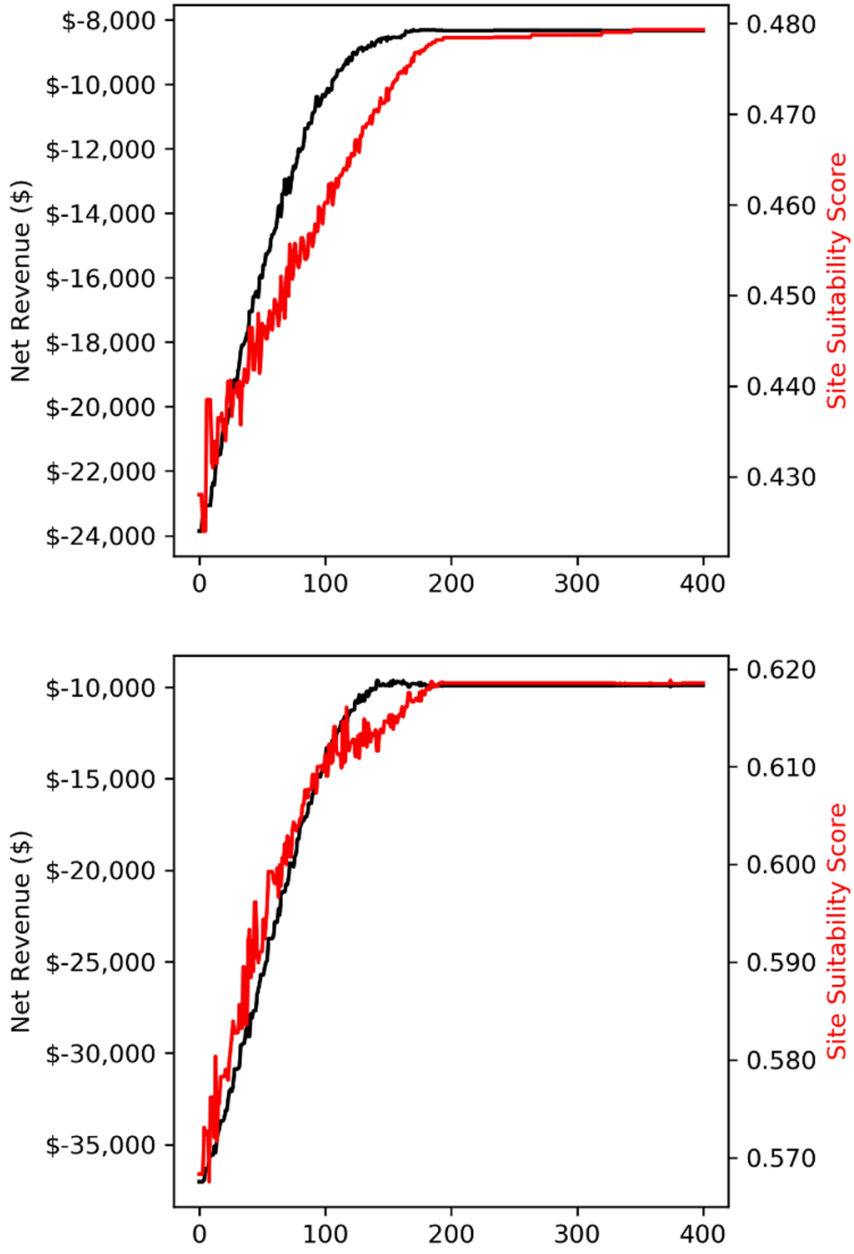

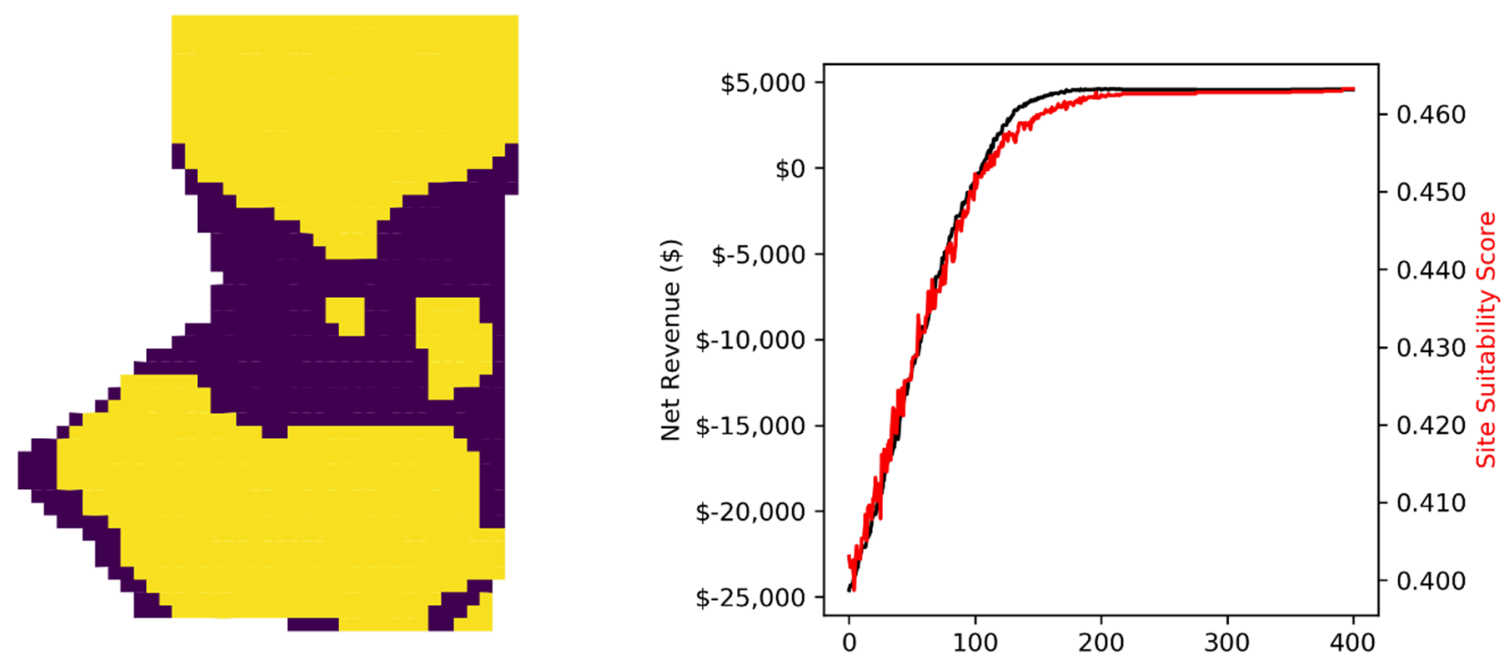

Field 542

Figure 10. Field designs (left) incorporation switchgrass production (left) and corn grain production (yellow) with plots (right) showing economic and SSI metrics during the evolutionary process.

\section{Conclusion}

The field designs generated using the subfield allocation method show that it is possible to reduce feedstock access costs by 30 percent and still generate improved economic and environmental outcomes at the field level. However, this process depends upon identifying suitable fields, allocating projected energy crop supplies to individual fields, developing accurate and industrially relevant subfield yield maps, and optimization methods to integrate energy and row crop production at subfield levels.

Over the past three years, substantial effort and progress has been made to develop ILM modelling capabilities to support reduced biomass feedstock access costs represented by grower payment assumptions. Farmers and/or land owners will not accept reduced payments by themselves to support an emerging bioeconomy. Instead, pathways must be developed to maximize the holistic value of integrating energy crop production in fields and subfield areas in ways that generate economic value and conditions supporting potential ES revenue streams.

Building upon the successes of LEAF, bioLEADS was developed to not only provide landscape assessment capabilities but to incorporate new modelling capabilities to support landscape- and field-level design efforts with an emphasis on reducing feedstock access costs to support BETO cost targets.

\section{$\underline{\text { References }}$}

De la Torre Ugarte, D, et al. 2000. "Biomass and bioenergy applications of the POLYSYS modeling framework." Biomass \& Bioenergy 18 (4):291-308. 
Gelfand, I., Sahajpal, R., Zhang, X., Izaurralde, R. C., Gross, K. L., \& Robertson, G. P. 2013. Sustainable bioenergy production from marginal lands in the US Midwest. Nature, 493(7433), 514-517.

Griffel, L. M., Hartley, D. S., \& Roni, M. 2018. Integrated Landscape Management TechnoEconomic Analysis Demonstrating 20 Percent Reduction in Biomass Production Costs. Idaho National Laboratory.

Griffel, L. M., Vazhnik, V., Hartley, D. S., Hansen, J. K., \& Roni, M. 2020. Agricultural field shape descriptors as predictors of field efficiency for perennial grass harvesting: An empirical proof. Computers and Electronics in Agriculture, 168, 105088.

Hanna, M. 2016. Estimating the field capacity of farm machines. https://ib.dr.iastate.edu/pubs_agdm/8/. Accessed Jan 2020.

Hellwinckel, Chad, et al. 2015. "Simulated impact of the renewable fuels standard on US Conservation Reserve Program enrollment and conversion." GCB Bioenergy 8:245-256. doi: 10.1111/gcbb.12281.

Langholtz, Matthew H., et al. 2014. "2013 Feedstock Supply and Price Projections and Sensitivity Analysis." Biofuels Bioproducts \& Biorefining-Biofpr 8. doi: 10.1002/bbb.1489.

Muth Jr, D. J., McCorkle, D. S., Koch, J. B., \& Bryden, K. M. (2012). Modeling sustainable agricultural residue removal at the subfield scale. Agronomy Journal, 104(4), 970-981.

Muth Jr, D. J., Bryden, K. M., \& Nelson, R. G. (2013). Sustainable agricultural residue removal for bioenergy: A spatially comprehensive US national assessment. Applied Energy, 102, 403417.

Nair, S. K., Hartley, D. S., Gardner, T. A., McNunn, G., \& Searcy, E. M. (2017). An integrated landscape management approach to sustainable bioenergy production. BioEnergy Research, 10(3), 929-948.

Roni, M., Thompson, D. N., Hartley, D., Griffel,G. M., Hu, H., Nguyen, Q., Cai, H.. 2018. Herbaceous Feedstock 2018 State of Technology Report. Idaho National Laboratory.

Roni, M., Lin, Y., Thompson, D. N., Hartley, D.,Cai, H.. 2019. Herbaceous Feedstock 2019 State of Technology Report. Idaho National Laboratory.

Roni, M., Thompson, D. N., Hu, H., Hartley, D. S., Nguyen, Q., Cai, H. 2017. Herbaceous Feedstock 2017 State of Technology Report. Idaho National Laboratory.

Toba, A. L., Griffel, L. M., \& Hartley, D. S. 2020. Devs based modeling and simulation of agricultural machinery movement. Computers and Electronics in Agriculture, 177, 105669. 
USDOE. 2011. U.S. Billion-Ton Update: Biomass Supply for a Bioenergy and Bioproducts Industry. Edited by R.D. Perlack and B.J. Stokes. Vol. ORNL/TM-2011/224. Oak Ridge, TN: Oak Ridge National Laboratory.

USDOE. 2016. ORNL/TM-2005/66. "2016 Billion-Ton Report: Advancing Domestic Resources for a Thriving Bioeconomy, Volume 1: Economic Availability of Feedstocks." Oak Ridge, TN. http://energy.gov/eere/bioenergy/2016-billion-ton-report

Jinzhuo Wu, Jingxin Wang \& Michael P. Strager (2011) A Two-Stage GIS-Based Suitability Model for Siting Biomass-to-Biofuel Plants and its Application in West Virginia, USA, International Journal of Forest Engineering, 22:2, 28-

38, DOI: $10.1080 / 14942119.2011 .10702608$ 